4.

Aus dieser Vergleichung geht hervor, dafs auch die drilte Reihe der Beobachtungen durch die Elemente sehr gut dargestellt wird; nur am $11^{\text {ten }}$ Februar überschreitet der Unterschied zwischen der Beobachtung und Rechnung die gewöhnliche Größse, und läfst einen Fehler im Anschreiben der Beobachtungen vermuthen. Unglïcklicherweise ist das Original gerade dieser Beobachtung, durch einen Zufall abhanden gekommen, weshalb nicht mehr entschieden werden kann, ob es genau gleichförmig in das Tagebuch eingetragen ist; der Verdacht eines Schreibfehlers allein, schien jedoch die Ausschliefsung einer sonst für gut zehaltenen Beobachtung nicht zu rechtfertigen, weshalb sie bei der Rechnung gleiches Recht mit den übrigen erhalten hat.

Die dritten Elemente stimmen mit den zweiten schon so nahe überein, dafs die erlangte Annäherung an die wahre Bewegung des Satelliten für sehr grofs gehalten werden inufs. Dennoch werde ich die Beobachtungen und ihre An- wendung zu weiteren Verfeinerungen der Elemente, noch fortsetzen, indem ich sie zu Grundlagen anderer Untersuchungen über das Saturns-System zu machen gedenke. Obgleich die Geringfügigkeit der den zweiten Elementen angebrachten Verbesserungen schon erwarten läfst, dafs die Uebereinstimmung der beiden ersten Beobachtungsreihen mit ihnen, sehr nahe so grofs sein wird als sie mit den früberen Elementen war, so führe ich doch an, dafs die Summe der Quadrate der Fehler jener beiden Beobachitungsreihen, durch die Verbesserungen der Elemente, nur um 0,302 gewachsen, also von 16,549 in 16,851 übergegangen ist; die dritte Reibe fuigt dieser Summe nur 6,882 hinzu, exscheint also als noch besser gelungen als die früheren.

Die gefundene mittlere Entfernung des Satelliten giebt die Saturnsmasse

$$
=\frac{1}{3501,6}
$$

und den mittleren Fehler des Nenners dieses Bruches $= \pm 1,15$ Einheiten.

$$
\text { Bessel. }
$$

\title{
Nachrichten über das Verschwinden des Saturnsringes.
}

In Königsberg war das Welter auch der Beobachtung der auf den $30^{\text {sten }}$ April angekündigten Verschwindung des Ringes höchst ungünstig, Am $23^{\text {sten }}$ April erschien die Lichtlinie an beiden Seiten des Planeten dem Verschwinden ziemlich nahe zu sein; wenigstens war sie augenfällig schwächer geworden als Tages vorher. Darauf fiel ununterbrochen trübes Wetter ein, welches erst am 30sten April erlaubte, den Saturn, bei sehr dunstigem Himmel wieder zu sehen; er erschien ohne Ring, so wie auch am $1^{\text {sten }}$
May unter gleichungünstigen Umständen. Am $3^{\text {tcn }}$ May war der Himmel heiter, vom Ringe aber war keine Spur mehr zu sehen. - Obgleich ich vor und nach dem Verschwinden des Ringes alle Aufmerksamkeit angewandt habe, um Lichtpunkte auf demselben zu entdecken, so habe ich doch keine sehen können; ich darf hierbei jedoch nicht unbemerkt lassen, dafs die Luft stets unruhig war und keine deutliche Bilder der Gegenstände gewährte.

Bessel.

Sternbedeckungen auf der Cracauer Sternwarte im Jahre 1832 beobachtet.

1832 Jänner 5. Eintrilt in den dunkeln Rand des Mondes von 9 Capricorni um Februar 10.

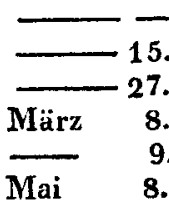

Septbr. 4. Decbr, 31 .

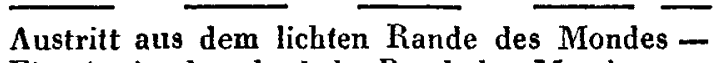

Eintritt in den dunkeln Rand des Mondes

- in den lichten Rand des Mondes - Venus

$\overline{\text { Eintritt des Saturn. }}$ Berührung des I Randes II

Volle Verschwindumg des Ringes .................

Austritt des II Saturnrandes.......................

Eintritt in den dunkeln Rand des Mondes von 390 Sagittar.
(225) Ceti b 1 ,

$\begin{array}{lllll}3 & 58 & 16,72 & \text { St. Z. }\end{array}$

34439,34

$4 \quad 4937,09$

$\begin{array}{llll}16 & 17 & 53,50\end{array}$

195626,26

9225,67

$1136 \quad 57,75$

14450,76

$\begin{array}{lll}14 & 6 & 10,76\end{array}$

$146 \quad 46,26$

$\begin{array}{lll}14 & 41 & 6,59\end{array}$

$2026 \quad 47,15$

43722,20 